\title{
ANALISIS KUAT TEKAN, KUAT TARIK DAN SIFAT FISIS SEMEN ORGANIK TERBUAT DARI BAHAN LIMBAH DAUR ULANG
}

\author{
Muhammad Syarif \\ Dosen Prodi Arsitektur, Fakultas Teknik Universitas Muhammadiyah Makassar \\ Email: muhsyarif00@gmail.com.
}

\begin{abstract}
ABSTRAK
Semen organik merupakan semen alternatif terbaru selain semen portland, dibuat dari mendaur ulang sampah organik, limbah batu bara berupa fly ash dan bottom ash serta mensubtitusi tanah mediteran dan tanah liat. Penelitian ini sebagai langkah kebijakan dalam penyelamatan lingkungan. Pengujian kuat tekan dan kuat tarik belah beton silinder menggunakan semen organik dan sebagai pembandingnya menggunakan semen portland melalui metode water curing dan dry curing pada umur 3,7,14,21 dan 28 hari. Hasil uji tekan beton menggunakan semen organik diperoleh 8,52 MPa pada metode water curing dan 14,52 MPa pada metode dry curing, sedang pada beton yang menggunakan semen portland yaitu 22,37 MPa pada metode water curing dan 19,71 MPa pada metode dry curing. Hasil uji kuat tarik belah menggunakan semen organik pada umur beton 28 hari mencapai 0,96 MPa pada metode water curing dan 1,22 MPa pada metode dry curing. Adapun yang menggunakan semen portland yaitu 2,03 MPa pada metode water curing dan 2,03 MPa pada metode dry curing. Hasil uji fisis berat jenis semen organik adalah 3,01 gr/m/ sedang untuk semen portland adalah $3.16 \mathrm{gr} / \mathrm{ml}$. Berat jenis semen organik $3,05 \mathrm{gr} / \mathrm{ml}$ dan berat jenis semen portland yaitu 3,15 gr/ml. Kehalusan butiran semen organik yang lolos pada ayakan 200 mesh sebanyak 56\%, lebih halus dari semen portland yaitu 52\%. Berat padat semen organik $1200 \mathrm{~kg} / \mathrm{m}^{3}$ lebih ringan dari semen portland yang mencapai $1250 \mathrm{~kg} / \mathrm{m}^{3}$. Waktu ikat awal semen organik adalah 105 menit dan waktu ikat akhir semen organik adalah ke 225. Untuk semen portland waktu ikat awalnya adalah 90 menit sedang waktu ikat akhirnya mencapai 180 menit.
\end{abstract}

Kata kunci: semen organik; semen portland; tanah mediteran; sampah organik.

\section{PENDAHULUAN}

Bahan alternatif yang sedang menjadi perhatian dewasa ini adalah pemanfaatan limbah-limbah industri dan limbah rumah tangga sebagai salah satu langkah penyelamatan lingkungan. Limbah industri maupun limbah rumah tangga untuk bahan campuran pembuatan suatu bahan bangunan dan diharapkan mampu mencapai spesifikasi yang layak sebagaimana layaknya jenis material yang telah dipergunakan sebelumnya.

Penelitian ini bertujuan untuk penyela matan lingkungan dari penumpukan limbah sampah yang tidak memberikan banyak konstribusi dalam kehidupan masyarakat selama ini dan sekaligus sebagai usaha penemuan bahan bangunan alternatif terbarukan. Kebutuhan bahan bangunan perlu disikapi dengan melakukan penelitian untuk pemanfaatan dan penemuan bahan bangunan yang mampu menjadi bahan alternatif. Kajian ekperimental yang telah dilakukan serangkaian dengan hal tersebut adalah mensubtitusi tanah mediteran dengan limbah melalui sistim daur ulang sampah organik yaitu limbah sampah rumah tangga, limbah batu bara berupa fly ash dan bottom ash, serta tanah mediteran dan tanah liat/clay menjadi semen organik, yaitu semen alternatif terbaru selain semen portland.

Kota makassar telah memproduksi sampah sebesar $4.000 \mathrm{~m}^{3}$ per hari (Oktovianus, 2015). Sampah dari hari kehari semakin meningkat produksinya sejalan dengan pertumbuhan penduduk yang semakin meningkat (Umar, 2009). Dengan melalui proses pembakaran, sampah organik akan menjadi abu yang mengandung unsur $\mathrm{SiO} 2$ sebanyak $23 \%$ $46 \%$, Al2O3 sebanyak $13 \%-29 \%$ dan $\mathrm{CaO}$ sebanyak 12\%-31\% (Priyatna, 2009). Dalam mempermudah penguraian sampah organik dan anorganik maka peran masyarakat sangat dibutuhkan (Wompere, 2012).

Meningkatnya produksi sampah maka
secara berangsur-angsur memberikan
dampak negatif terhadap lingkungan dan
penduduk (Waryono, 2009). Tingginya
volume sampah sehingga dipandang perlu


umtuk melakukan pengelolaan (Suarna, 2008).

Peningkatan kebutuhan akan perumahan maupun infrastruktur secara otomatis menuntut kebutuhan akan bahan bangunan yang semakin meningkat pula. Peningkatan akan kebutuhan bahan bangunan harus disikapi dengan pemanfaatan dan penemuan bahan bangunan yang mampu memberikan alternatif. (Syarif Muhammad, dkk, 2017).

Semen organik merupakan semen alternatif terbaru selain semen portland yang merupakan kajian ekperimental yang telah dilakukan sebagai bentuk pemanfaatan daur ulang sampah organik, limbah fly ash,limbah bottom ash dan subtitusi tanah mediteran serta tanah liat (Syarif Muhammad, 2017).

Semen yang mengandung unsur mineral sebagai pengganti sebagian semen Portland dikenal sebagai semen komposit, semen campuran atau semen alternatif. Komponen mineral yang ditambahkan disebut mineral tambahan yang bersifat reaktif dan berkontribusi terhadap proses hidrasi proses. Terak atau fly ash paling banyak digunakan serta tambahan mineral lainnya berupa pozzolans alami dan microsilica/silica fume (Winter B Nicholas, 2014).

Nilai kuat tarik lentur terbesar pada beton umur 14 hari dengan penambahan abu ampas tebu sebanyak 5\% maka beton akan memiliki kuat tarik lentur sebesar $6.221 \mathrm{MPa}$ atau mengalami kenaikan kekuatan $2.45 \%$ dari beton tanpa menggunakan tambahan abu ampas tebu (Gerry Phillip Rompas dkk, 2013). Penggunaan fly ash jenuh merupakan salah satu cara untuk mengurangi penguapan tinggi dalam proses hidrasi terhadap kepadatan semen dalam beton (Victor Sampebulu, 2012).

Tanah mediteran adalah tanah yang sifatnya tidak subur dan yang terbentuk dari pelapukan batu kapur yang memiliki kandungan kalsium dan magnesium, jenis tanah mediteran tidak banyak memberi keuntungan untuk pertanian namun jenis tanah ini sangat baik digunakan untuk bahan bangunan. (Sanico Maria, 2012).

\section{METODE PENELITIAN}

Pengukuran nilai kuat tekan dan nilai kuat tarik belah beton silinder pada pengujian ini menggunakan metode water curing dan metode dry curing terhadap beton benda uji yang berbentuk silinder dengan ukuran tinggi $20 \mathrm{~cm}$ dan diameter $10 \mathrm{~cm}$. Pengujian kuat tekan beton dilaksanakan pada umur benda uji 3 hari, 7 hari, 14 hari, 21 hari, dan 28 hari sedang untuk pemeriksaan kuat tarik belah pada umur benda uji 28 hari. Jumlah benda uji kuat tekan untuk beton menggunakan semen organik maupun untuk semen portland masing-masing dibuat 15 buah. Sedang untuk pengujian kuat tarik belah masing-masing sebanyak 2 buah. Pengujian dilakukan dengan menggunakan alat Universal Testing Machine (UTM). Uji kuat tekan berdasarkan ASTM C 39/C39M-05. Untuk membentuk konsentrat semen organik, semua bahan utama dikompositkan dan dibakar hingga suhu $1400^{\circ} \mathrm{C}$.

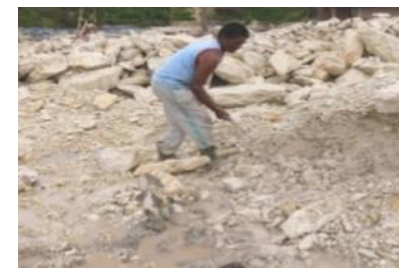

A
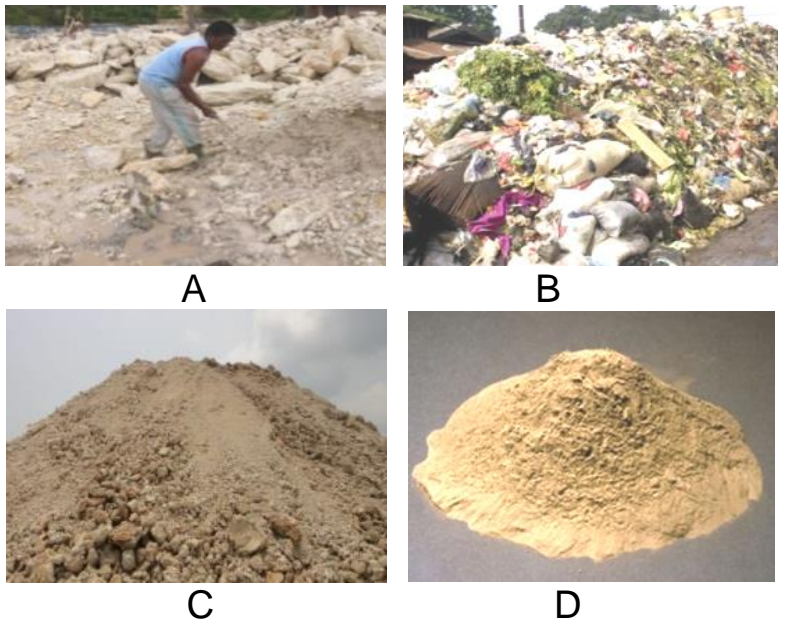

$\mathrm{B}$
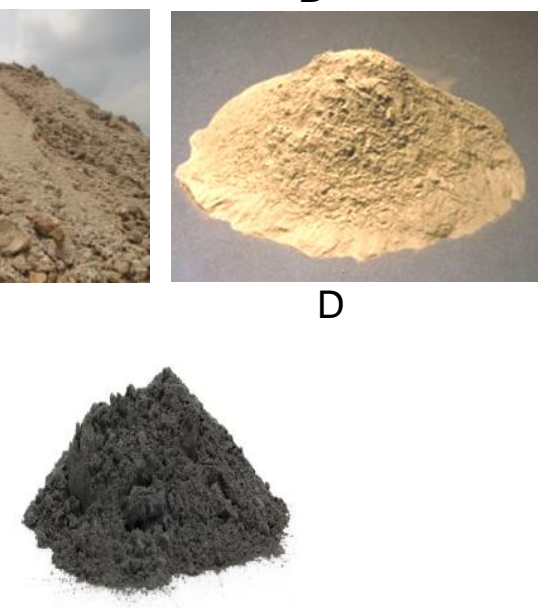

E
Gambar 1. Tanah Mediteran (A), Sampah Organik (B), Tanah Liat (C), Fly ash (D), Bottom Ash (E)

\section{HASIL DAN PEMBAHASAN}

Konsentrat semen organik dibentuk dengan memanfaatkan substitusi bahan alami berupa tanah mediteran dan daur ulang 
limbah organik yang merupakan limbah rum tangga, fly ash, bottom ash dan tanah liat. Dalam melakukan pengujian kuat tekan (compressive strength) dan pengujian kuat tarik belah (splitting test) maka beton silinder sebagai sampel uji memiliki variabilitas karakteristik yang sangat mempengaruhi kekuatan yang terbentuk pada beton saat dilakukan pengujian kekuatan terhadap daya dukung tekan dan tariknya.

Kuat tekan beton adalah besarnya beban persatuan luas yang menyebabkan benda uji beton hancur bila dibebani dengan gaya tekan tertentu, yang dihasilkan oleh mesin tekan.

\section{Uji Kuat Tekan (Compressive Strength)}

Hasil pengujian kuat tekan silinder beton yang menggunakan semen portland pada metode water curing menghasilkan 22,37 $\mathrm{MPa}$ sedang untuk metode dry curing menghasilkan 19,71 MPa. Untuk beton semen organik pada metode perawatan water curing menghasilkan 8,52 $\mathrm{MPa}$ sedang untuk metode dry curing menghasilkan 14,52 Mpa. Gambar 2 merupakan grafik hasil pengujian kuat tekan (compressive strength).

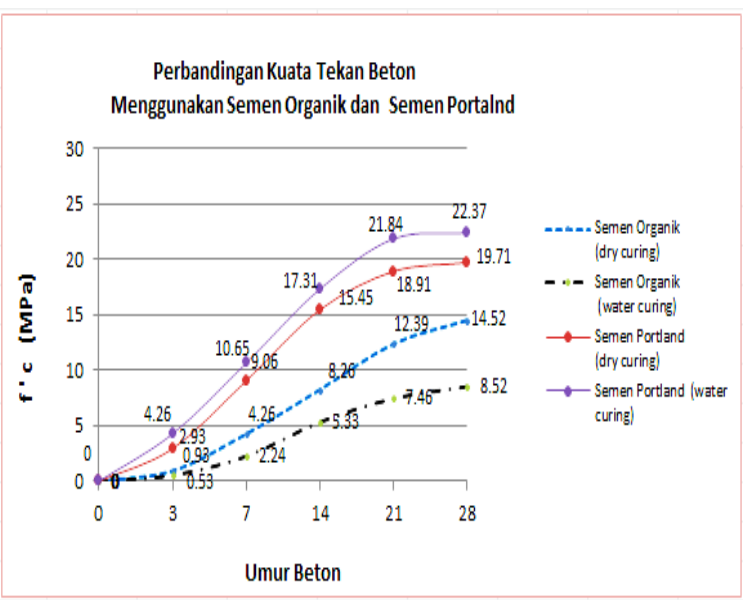

Gambar 2. Grafik perbandingan hasil uji kuat tekan beton menggunakan semen organik dan yang menggunakan semen portland

Besarnya nilai kuat tekan benda uji yang dihasilkan dihitung dengan acuan standar normatik menggunakan rumus sesuai ASTM C-39/39M-05 dan SNI 03-6815-2002 dengan rumus :

$$
\sigma=\frac{P}{A}\left(\mathrm{~kg} / \mathrm{cm}^{2}\right)
$$

Dengan :

$$
\begin{aligned}
\sigma= & \text { Tegangan tekan karakteristik } \\
& \text { beton }\left(\mathrm{kg} / \mathrm{cm}^{2}\right), \\
\mathrm{P}= & \text { Gaya tekan }(\mathrm{Kg}) \\
\mathrm{A}= & \text { Luas penampang bidang tekan } \\
& \text { silinder beton }\left(\mathrm{cm}^{2}\right) .
\end{aligned}
$$

Gambar 3 merupakan proses pengujian kuat tekan beton silinder yang menggunakan semen organik dan yang menggunakan semen portland.

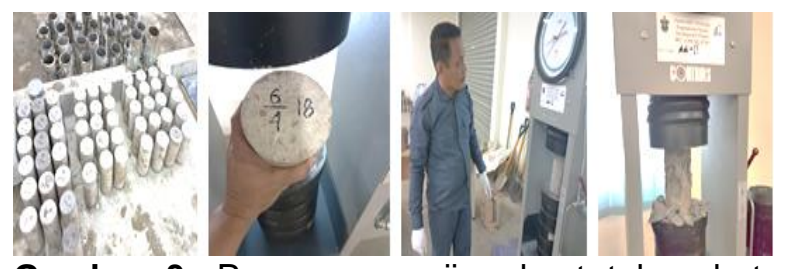

Gambar 3. Proses pengujian kuat tekan beton silinder

\section{Uji Kuat Tarik Belah (Tensile Spliting Test)}

Perlakuan uji kuat tarik belah atau tensile spliting cylinder test. yang menyatakan ukuran ketahanan material terhadap tekanan mekanis dan tekanan panas (thermal stress). Dalam pengujian kuat tarik belah silinder dinyatakan bahwa kekuatan tarik beton (ft) biasanya berkisar 0,05 sampai 0,1 dari nilai kuat tekannya (Munaf Rezaldy Dicky, 2011).

Besarnya nilai kuat tarik belah benda uji yang dihasilkan dihitung dengan menggunakan rumus berdasarkan acuan normatif dari ASTM C-496-965 dan SNI 03-2491-2002 sebagai berikut :

Kuat Tarik Belah $\rightarrow$ fct $=\frac{2 \times P}{L D}$

Dengan: fct $=$ Kuat tarik-belah $(\mathrm{MPa})$,

$$
\begin{aligned}
& \mathrm{P}=\text { Beban uji maksimum }(\mathrm{N}) \\
& \mathrm{L}=\text { Panjang Benda Uji }(\mathrm{mm}) \\
& \mathrm{D}=\text { Diameter benda uji }(\mathrm{mm})
\end{aligned}
$$

Kuat tarik belah yang menggunakan semen portland dengan metode perawatan water curing menghasilkan 2,03 MPa sedang yang menggunakan semen organik adalah 0,96 $\mathrm{MPa}$. Gambar 4 merupakan grafik perbandingan kuat tarik metode water curing pada sampel beton yang menggunakan semen organik dan yang menggunakan semen portland. 


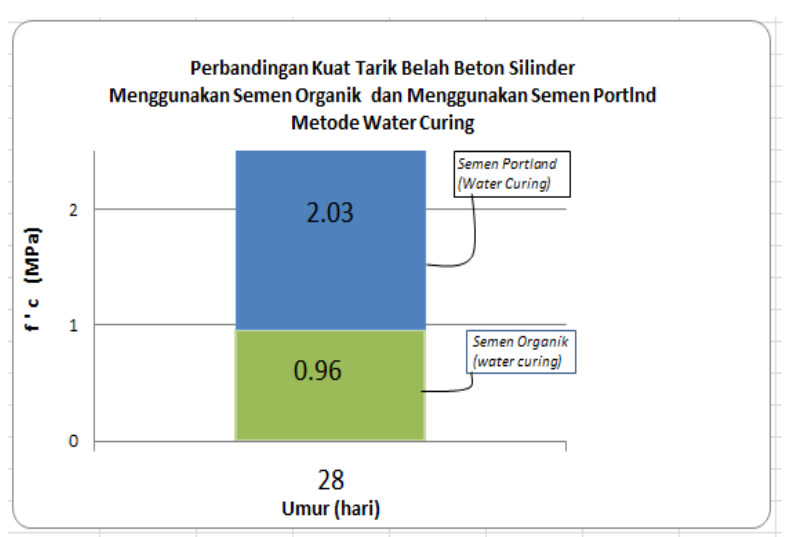

Gambar 4. Grafik perbandingan kuat tarik beton silinder metode water curing

Kuat Tarik belah pada metode dry curing menghasilkan 1,59 Mpa untuk beton yang menggunakan semen portland dan 1,22 MPa untuk beton yang menggunakan semen organik. Gambar 5 adalah grafik perbandingan kuat tarik beton silinder metode dry curing.

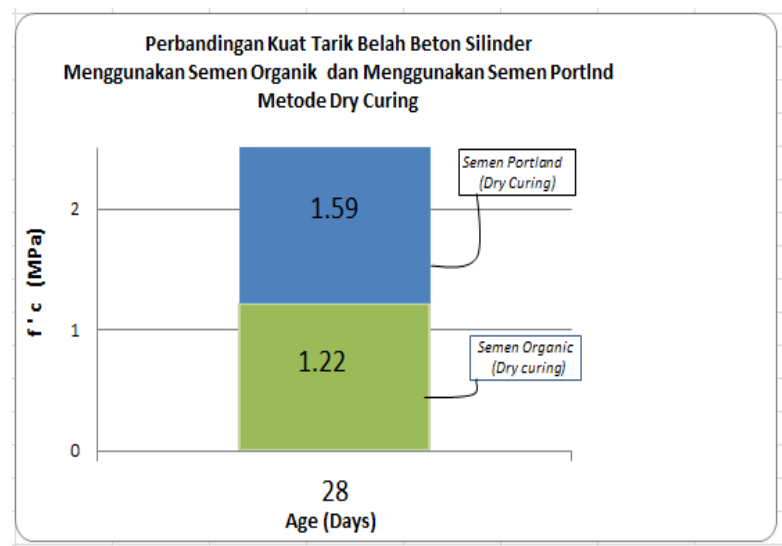

Gambar 5. Grafik perbandingan kuat tarik beton silinder metode dry curing

\section{Kehalusan butiran}

Semakin halus semen, maka permukaan butirannya akan semakin luas sehingga persenyawaannya dengan air akan semakin cepat dan membutuhkan air dalam jumlah yang besar pula.

Nilai kegemburan/kehalusan untuk semen organik yang lolos pada ayakan 200 mesh sebanyak $56 \%$ dengan berat padat 1200 $\mathrm{kg} / \mathrm{m}^{3}$ sedang untuk semen portland sebanyak $52 \%$ dengan berat padat $1250 \mathrm{~kg} / \mathrm{m}^{3}$. Menurut Kimberly Kurtis (2010), bahwa berat jenis (specific gravity) semen portland sebesar 3,15 $\mathrm{gr} / \mathrm{ml}$. Dari hasil penelitian ini diperoleh berat jenis semen organik sebesar 3,05 gr $/ \mathrm{ml}$.

Gambar 6 A adalah proses pengujian kehalusan semen organik. Gambar 6 B merupakan proses pengukuran berat jenis semen organik.

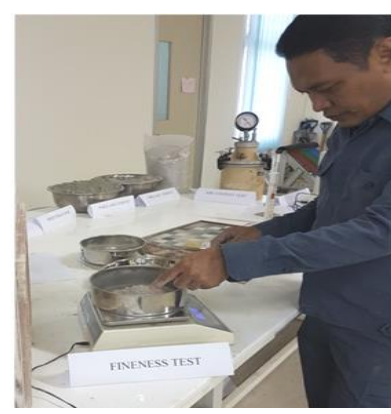

A

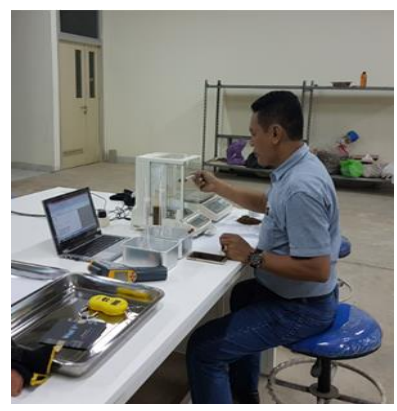

B
Gambar 6. Proses pengujian kehalusan dan berat jenis semen organik

\section{Waktu ikat}

Semen sebagai perekat hidrolis memiliki sifat mengikat air sehingga semen akan mengeras apabila senyawa yang terkandung didalamnya telah bereaksi dengan air. Waktu ikat adalah waktu yang diperlukan semen untuk mengeras terhitung dari mulai bereaksi dengan air dan menjadi pasta semen, hingga pasta semen cukup kaku untuk menahan tekanan sebagaimana yang ditunjukkan pada gambar 7. Waktu ikat semen dibedakan menjadi 2 yaitu :

\section{waktu pengikatan awal (initial setting)}

Pengujian waktu pengikatan awal (initial setting) semen portland diuji dengan metode jarum vicat diameter $1 \mathrm{~mm}$ yang menembus pasta semen sedalam $24 \mathrm{~mm}$ terjadi pada menit ke-90 setelah jarum tersebut dilepaskan. Kadar air yang digunakan untuk pengujian pengikatan adalah kadar air konsistensi normal (25\%). Pengujian konsistensi normal mengacu pada ASTM C187-04. Waktu ikat awal semen organik dengan metode jarum vicat diameter $1 \mathrm{~mm}$ yang menembus pasta semen sedalam 25 $\mathrm{mm}$ berlangsung pada menit ke-105 setelah jarum tersebut dilepaskan. Kadar air yang digunakan untuk pengujian pengikatan awal semen organik adalah kadar air konsistensi normal (37\%). Menurut standar ASTM C-191- 
04 dan ASTM C-191-08, waktu pengikatan awal tidak boleh kurang dari 45 menit.

\section{Waktu pengikatan akhir (final setting).}

Pengujian waktu pengikatan akhir (final setting) semen portland berada pada menit ke 180 , sedang untuk semen organik berada pada menit ke 225. Menurut standar SNI 036827-2002 waktu pengikatan akhir tidak boleh lebih dari 375 menit.

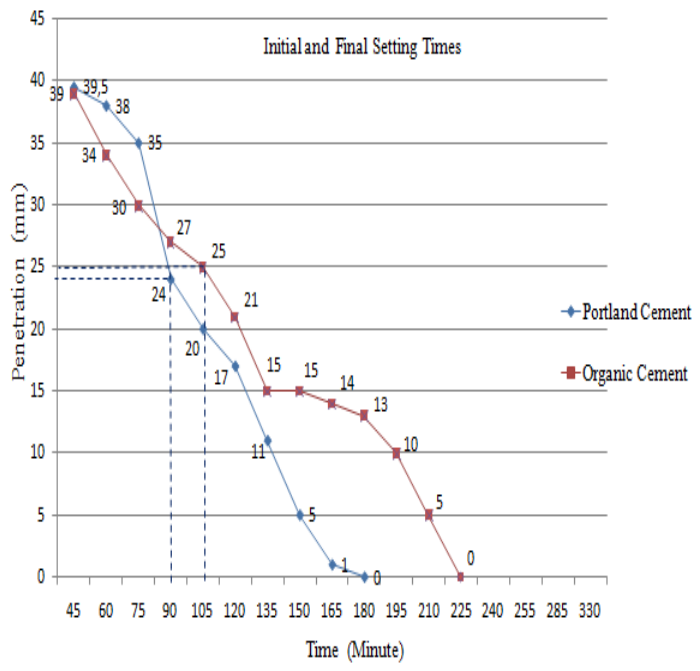

Gambar 7. Grafik waktu ikat awal dan akhir

Gambar 8 merupakan silinder beton yang dibuat dari konsentrat semen organik dan semen portland. Pada gambar tersebut juga menunjukkan proses pengukuran suhu dan berat benda uji. Dalam pengujian ini menggunakan pembanding sampel beton yang bahan utamanya menggunakan semen portland.

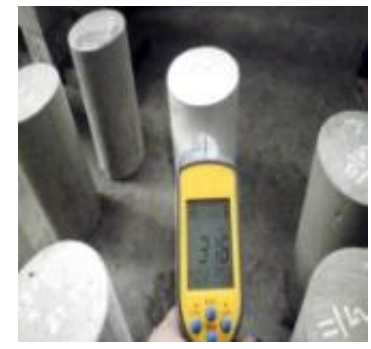

A

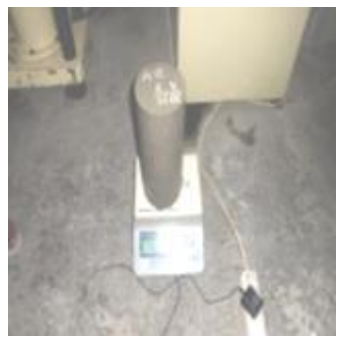

B

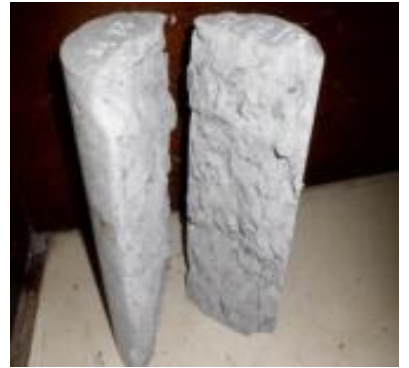

C

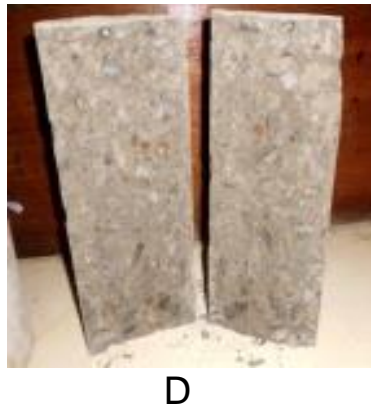

D
Gambar 8. Pengukuran suhu beton silinder dengan semen organik (A), Pengukuran berat beton silinder dengan semen organik (B), Silinder beton semen organik hasil uji tarik belah (C), Silinder beton semen portland hasil uji tarik belah (D)

\section{SIMPULAN}

Dari hasil pengujian kuat tekan dan kuat tarik belah beton silinder yang menggunakan konsentrat semen organik telah diperoleh indikasi kemampuan menahan beban tekan dan tarik serta memiliki sifat fisis yang menyerupai kemampuan daya dukung pada beton semen portland meskipun kemampuan daya tahan semen organik masih berada dibawah daya tahan semen portland yang dalam hal ini digunakan sebagai sampel pembanding. Adapun hasil pengujian sifat fisis yang dimiliki semen organik berdasarkan kajian empiris adalah mendekati acuan normatif pada Standar Nasional Indonesia (SNI) dan ASTM.

Untuk memperoleh pendekatan kelayakan yang lebih maksimal terhadap semen organik sebagai semen alternatif maka dipandang perlu untuk melakukan kajian eksperimental lanjutan agar kualitas semen organik dapat sesuai yang diharapkan berdasarkan acuan American Standard Testing And Material (ASTM) dan Standar Nasional Indonesia (SNI). 


\section{DAFTAR PUSTAKA}

American Society for Testing and Material/ASTM. (2006). Designation C 187-04 Standard Test Normal Consistency Of Hydraulic Cement. Copyright ASTM, PA19428-2959 United states.

American Society for Testing and Material, (ASTM), Designation C 39/C39M-05, Standard Test Methods For Compressive Strength Of Cylindrical Concrete Specimens, Licensee Purdue University/ 5923082001, 2009 06/25/2009.

American Society for Testing and Material, (ASTM), Designation C 496//C966M-17, Standard Test Methods For Splitting Tensile Strength Of Cylindrical Concrete Specimens, Licensee Purdue University/5923082001, 2009 06/25/2009.

American Society for Testing and Material/ ASTM. (2008). Designation C 191-04,"Standard Test Methods For Time Of Setting Of Hydraulic Cement by Vicat Needle". P 1-10, Current Edition Approved, June 1, 2008. Published July 2008. Annual book Of ASTM Standards, Vol 14.01

American Society for Testing and Material/ASTM. (2008). Designation C 191-08,"Standard Test Methods For Time Of Setting Of Hydraulic Cement by Vicat Needle". P 1-8, Current Edition Approved, June 1, 2008. Published July 2008. Annual book Of ASTM Standards, Vol 14.01

Standar Nasional Indonesia, SNI 03-6827-2002. Metode Pengujian Waktu Ikat Awal Semen Portland Dengan Menggunakan Alat Vicat.

Standar Nasional Indonesia,(1990). SNI 03-6815-2002. Metode Pengujian Kuat Tekan Beton

Standar Nasional Indonesia,(2001). SNI 03-2491-2002. Metode Pengujian Kuat Tarik Belah Beton

Gerry Phillip Rompas, dkk. Jurnal Sipil Statik Vol.1 No.2, hal (82-89). ISSN 2337-6732 (Januari 2013).

Munaf Rezaldy Dicky, dkk (2011). Buku "Material Semen dan Beton" Fakultas Teknik Sipil dan Lingkungan, Penerbit Institut Teknologi Bandung (ITB).

Priyatna dalam Edi Hartono. (2009). Penggunaan Campuran Abu Sampah Organik dan Limbah Karbit sebagai Bahan Pengganti Semen pada Mortar. Universitas Sumatra Utara Vol. 12, No.1, 86-91.

Sampebulu' Victor. (2012). "Influence Of High Temperature On The Workability Of Fresh Ready-Mixed Concrete" ITB Engineering, Vol. 44, No. 1, 2012, 21-32 ISSN 1978-3051.

Syarif Muhammad et al., (2017). "A study Of Cement Made From Recycled Gerbage Materials Compared With Portland Cement". The Third International Cenference on Sustainable Infrastructure and Built Environment (SIBE-2017) in Institut Teknologi Bandung (ITB), held on September 26-27-2017.

Syarif Muhammad, (2017). "Karakteristik Sampah Organik dan Tanah Mediteran Menjadi Semen Organik". Prosiding Vol 2, ISBN 978-602-60662-3-7, MTR 23-29. Konferensi Nasional Teknik Sipil 11 (KONTEKS-11) di Universitas Tarumana-gara Jakarta, tgl 26-27 Oktober 2017.

Winter B Nicholas. "Understanding Cement, Low Concrete Strenght, Ten Potential Cement-Related Causes" Copyright WHD Microanalysis Consultan Ltd. United Kingdom (2014)

Wompere Marten. (2012). "Butuh Regulasi Pengelolaan Sampah". Diakses dari http://www. jurnas.com/halaman/ 16/2012-01-13/195452.

Kurtis Kimberly, (2010). Tests on Portland Cement. School of Civil Engineering Georgia Institute of Technology Atlanta, Georgia. (book, page 1-27).

Sanico Maria, 2012. "Tanah Mediteran” http:// laptopchep.blogspot.co.id/2012/01/tanah -mediteran.

Oktovianus, (2015). Pengelolaan Sampah di Kota Makassar Dengan Bank Sampah. http://artikelopiniku.blogspot. co.id/2015/08/pengelolaan sampah di kota makassar .html.

Suarna, I Wayan.(2011). "Model Penanggula-ngan Masalah Sampah Perkotaan dan Pedesaan". Pusat Penelitian IImiah Lingkungan Hidup Universitas Udayana. Dies Natalis 2008 Universitas Udayana, diakses dari http://www.dies.unud.ac.id/wp

Umar, Ibnu.(2009). "Pengelolaan Sampah Secara Terpadu Diwilayah Perkotaan". Artikel Nasional, diakses diakses dari;https:// uwityangyoyo. wordpress. com/2009/04/05 /pengelolaan-sampah-secaraterpadu-di-wila-yah- perkotaan.

Waryono,Tarsoen. (2009) "Konsepsi Pena-nganan Sampah Perkotaan Secara Terpadu Berkelanjutan". Kumpulan Makalah periode 1987-2008, https://staff.blog.ui. ac.id/tarsoen.waryono/files/2009/12/46konsepsi-penanga-nan-sampah-perko-taan. 